\title{
Community Health Workers: Challenges and Vulnerabilities of Accredited Social Health Activists Working in Conflict-affected Settings in the State of Assam, India
}

Preety R Rajbangshi ( $\sim$ prajbangshi@georgeinstitute.org.in )

George Institute for Global Health https://orcid.org/0000-0002-1831-4548

Devaki Nambiar

The George Institute for Global Health

Aradhana Srivastava

WFP: World Food Programme

Research

Keywords: Community health workers, Assam, India, Conflict

Posted Date: December 18th, 2020

DOI: https://doi.org/10.21203/rs.3.rs-130225/v1

License: (a) (i) This work is licensed under a Creative Commons Attribution 4.0 International License. Read

Full License 


\section{Abstract}

Introduction:. It is well acknowledged that India's Community Health workers known as Accredited Social Health Activists (ASHA) are the bedrock of its health system. Many ASHAs are currently working in fragile and conflict-affected settings. No efforts have yet been made to understand the challenges and vulnerabilities of these female workers. This paper seeks to address this gap by bringing attention to the situation of ASHAs working in the fragile and conflict settings and how conflict impacts them and their work.

Methods: Qualitative fieldwork was undertaken in four conflict-affected villages in two conflict-affected districts -Kokrajhar and Karbi Anglong of Assam state situated in the North-East region of India. Detailed account of four ASHAs from the majority (Bodo or Karbi) and minority (Adivasi or Koch) communities serving roughly 4000 people is presented. Data transliterated into English were analysed by authors by developing a codebook using grounded theory and thematic organisation of codes.

Results: ASHAs reported facing challenges in ensuring access to health services during and immediately after outbreaks of conflict. They experienced difficulty in arranging transport and breakdown of services at remote health facilities. Their physical safety and security were at risk during episodes of conflict. ASHAs reported hostile attitudes of the communities they served due to the breakdown of social relations, trauma due to displacement, and loss of family members, particularly their husbands.

Conclusion: Conflict must be recognised as an important context within which community health workers operate, with greater policy focus and research devoted to understanding and addressing the barriers they face as workers and as persons affected by conflict.

\section{Introduction}

India's Community Health Workers (CHWs), known as Accredited Social Health Activists (ASHAs), are the bedrock of its health system. Nearly one million trained ASHAs are working as volunteers in the largest government-led CHW programme globally (1). These workers receive performance-based incentives linked to different health programmes implemented by Indian states. ASHAs are female residents of the villages they serve; they are the interface between their communities and the health system. Their main role is to generate awareness in their communities about health and its determinants and support the delivery of primary health care (2). Several evaluations of the ASHA programme have established their contribution towards improved awareness, behaviour change, and positive impact on the health and well-being of the communities they serve(1-4). Concurrently, an extensive global body of literature suggests and supports CHWs effectiveness in the delivery of primary healthcare programmes in different settings(5). For example, several humanitarian organizations have established $\mathrm{CHW}$ programmes as a means to increase access to health services during and after humanitarian emergencies (5). Conflict-affected health systems in countries like Afghanistan, Burkina Faso have also engaged $\mathrm{CHWs}$ to provide essential services under restrictive and sometimes dangerous situations (6). CHWs work in all of the conflict -affected regions of india, which include the erstwhile state of Jammu and Kashmir as well as six of the eight states in the northeast region. 
While the current literature globally offers guidance on the effectiveness of CHWs and optimizing their performance, the challenges and vulnerabilities of $\mathrm{CHWs}$ working in fragile and conflict-affected settings remain inadequately understood within the field of human resources for health. There is a scarcity of studies to inform the determinants of CHWs' performance in fragile and conflict settings, and the need for such evidence is pressing (5). This paper seeks to address this gap by bringing attention to the situation of CHWs working in the fragile and conflict settings, and the impact of conflict on them and their work.

We present the findings from a larger study on women's reproductive health access conducted in the conflictaffected state of Assam in the North-East region of India. Assam is a multiethnic and multilingual state with 31 million people (7). It has been one of the most volatile and sensitive states in the region; for more than half a century, the state has witnessed conflicts ranging from insurgency for autonomy and domestic terrorism to ethnic violence (8). There are several extremist outfits in the state aiming to achieve different objectives based on ethnicity and territory (8). Currently, conflict in Assam is shaped by ethnic polarization and the assertion of community identities. This includes resistance to the settlement of perceived foreigners from Bangladesh [faced by Bengali speaking Muslims], inter-tribal hostilities, and alienation of non-tribal migrant communities belonging to different states in India. While conflict is on the decline and confined to seven out of 33 districts of Assam, its effect is evident in these districts in the form of destruction of social infrastructure $(9,10)$.

This study was conducted in two conflict-affected settings - Kokrajhar and Karbi Anglong districts in Assam. The conflict in both the districts started with the struggle for a separate homeland for tribal communities: the Bodo in Kokrajhar and Karbi in Karbi Anglong district. This was followed by waves of ethnic conflict in both districts. The conflict in Kokrajhar is the oldest as it started in the late 1980s in the form of a violent movement for a separate homeland, continuing into the 1990s until 2003(9). This was followed by waves of ethnic conflict from 1996 onwards between the tribal Bodo community and non-tribal ethnic groups Santhal or Adivasi and Bengali speaking Muslims, led by militant groups belonging to the Bodo community seeking to drive out non-Bodos and create ethnically more homogenous region known as Bodoland Territorial Council $(9,11)$. In the past 25 years, Kokrajhar has seen eight waves of ethnic conflict $(9,12)$. In line with Kokrajhar, the conflict in Karbi Anglong started with a demand for statehood in the 1990s which was followed by inter-tribal conflict led by militant groups representing different tribal communities(10). Apart from repeated conflicts, both the districts are vulnerable to pervasive militant conflict. A study in Kokrajhar found that decades of conflict have weakened the social fabric and infrastructure of the district (9). This has increased health systems fragility and weakened the provision of health services to the majority rural population.

In both districts, ASHAs have been pivotal in building linkages between the health systems and community and support access to public health services. The ASHAs in Kokrajhar and Karbi Anglong districts are among the first to be recruited and trained in India, as Assam was one of the 18 states where the ASHA programme was first launched in 2006 under National Rural Health Mission (presently known a National Health Mission) (13). The training, responsibilities, incentive, and supervision system for ASHAs in the state was primarily based on the Federal Ministry of Health's guidelines for the ASHA programme with modifications based on the state's requirements and policies. 


\section{Methods}

A qualitative, descriptive study was conducted to understand the impact of conflict on reproductive health service delivery and utilization in conflict-affected districts. As a part of the larger qualitative study, in-depth interviews were conducted with health providers ranging from ASHAs to doctors and nurses rendering health services in the conflict-affected villages. In this paper, we present detailed accounts of four ASHAs on their experiences of providing health services in conflict-affected areas serving roughly 4000 people in four villages (each ASHA catering to roughly 1000 people), as well as the challenges they faced as front line health workers.

Formal permissions and support from the state and district health system were obtained for the larger study. Consultations with the District Programme Management Unit were held to select the block and villages affected by conflict. After selecting the villages, ASHAs were contacted in advance by three-member research teams comprising of the lead author, field investigator, and translator. A mix of purposive and convenience sampling methods was used for in-depth interviews with ASHAs.

Before data collection, training was imparted to the field investigator and translators of the respective district by the lead author. The focus was to orient the team with an interview guide, informed consent procedure, and ethical considerations. All interviews were conducted after receiving written consent from the participants. Interviews were conducted in either Assamese or the local dialect - Bodo or Karbi, depending on each participant's preference. The interviews in the Assamese language were carried out by the lead author and for all others, the help of a translator was taken. All interviews were conducted in ASHAs residence and audio-recorded after taking permission. Each interview lasted between 30-45 minutes. The lead author and field investigator took field notes after each day's fieldwork and these were discussed with the translators for their inputs and reflections. All interview recordings were stored in a folder accessible only to the research team. Interviews conducted in the Assamese language were transcribed by the field investigator and transcribers were engaged to transliterate from Karbi and Bodo dialect to the English language to obtain verbatim transcripts. The lead author performed quality checks. All transcripts were cleaned and entered into Atlas. Ti software version 8 .

An inductive conceptual framework was developed for the larger study and this framework was used to develop a codebook using grounded theory(14). The codebook was developed through coding using Atlas. Ti followed by a discussion among the three authors. Codes were reviewed and finalized, following which codes were organized thematically, and indexed to facilitate interpretation. The themes discussed in this paper emerged in the transcripts of ASHAs.

\section{Results}

The cases of four ASHAs are presented under two broad categories: (1) challenges of ASHAs in providing health services and (2) post-conflict vulnerabilities of ASHAs as women residing in conflict-affected communities. In most cases, the ASHAs we spoke noted that their experiences were common to other ASHAs working in conflict-affected areas. 


\section{Challenges of ASHAs in ensuring access to health services}

\section{Transportation difficulties}

In our discussions, ASHAs noted that during the conflict, the main challenges were poor transport linkages and communication. One worker, Sarita [name changed], pointed out the great difficulty faced by all ASHAs when the drivers of 108 emergency or 102 ambulatory services (implemented by the State National Health Mission) would refuse services and the family members of the pregnant woman would expect the ASHA to arrange transportation.

Figure 1 describes challenges faced by Sarita, as narrated by her, during the conflict where the family members of a pregnant woman approached and informed her that labour pain had started. She went with them and saw that the woman was in pain. Sarita immediately called 108 ambulance services but they refused to send a vehicle and asked her to make other arrangements. She even tried contacting drivers of private vehicles in the village but they too refused. In the meantime, she contacted the Community Health Officer at the sub-center (SC) and Medical Officer (In-charge) at the Primary Health Center (PHC) but they too could not help her. With no option left, the delivery was conducted at home: the woman suffered pain for two days and gave birth to a stillborn.

This difficulty in arranging transportation remained even months after the conflict episode and was reportedly due to pervasive fear among the drivers - both in the public and private sectors - of being stopped and beaten by army personnel. Another such instance was shared by Sarita where she had to take a pregnant woman 15 days after the conflict had ended. That day, both 108 emergency service and 102 ambulances refused. She tried contacting private vehicles and luckily one auto-driver agreed to drive them to the health facility. However, while returning, as the driver was alone, army personnel stopped and beat him up for driving at the time of conflict. Because of this incident, the drivers were afraid and one auto-driver placed a condition that he would take pregnant woman only if Sarita returned with him and did not stay in the health facility along with the pregnant woman. This condition placed her in a dilemma as the health system expected her to be present during delivery and if she were to refuse the driver, this would affect his willingness to transport this and other pregnant women in the future.

She further noted that the situation after conflict remained volatile for a few weeks, but she had accompanied pregnant women to the health facility for delivery by ignoring her fear: "we had to take them [pregnant women] even if we were scared to travel on the road as we had no other options."

Another challenge during the conflict was the breakdown of health services at the peripheral health facilities such as SC and PHC providing primary health care. Many times, ASHAs were left with the option of accessing the district hospital, which was already far away from their village and all the more difficult to reach at the time of conflict.

We found that there was no support mechanism to ease the difficulty faced by ASHAs in ensuring access to health facilities during the conflict. It was left to ASHAs to arrange transportation for reaching the health 
facility. We noted that their challenges remained unaddressed.

Another ASHA, Junali [name changed] noted that she had been displaced from her native village, but was still covering 10 households in that location (she is formally listed as the ASHA from this village) and the areas where the people were residing after displacement. She noted that the distance affected her performance as she had to visit three places to mobilize communities for immunization and other services.

\section{Unpaid labour}

Anita [name changed] noted that at the time of conflict she was engaged in a relief camp and supported the health staff in providing health services. According to her, all staff including ASHAs were expected to be available to provide services in relief camps, but there was no provision to pay for the work done by her and other ASHAs. She felt that it was her duty to provide health services; but also noted that she knew that the health system had funds for her work, but did not provide compensation. There was a feeling that ASHAs labour was not recognized.

"We have to be bold and leave our home and family to help them [health system]. The Sir's [doctors and district health officials] only tell us to do the work but don't think about us even once. They need to look at our pain and problems... We work so hard at the relief camps, leaving our home and families, for such a long time. Even if we are afraid, we have to be bold and yet we don't get any incentives or salary. We are expected to do the work for free. But we don't back out and do our jobs as soon as we get our orders [from health officials]."

\section{Physical safety and security}

A common concern was over the safety of ASHAs and other frontline female health workers such as Auxiliary Nurse Midwives during the conflict. They were expected to reach the relief camps or place of duty on their own. Although Anita reported working amidst fear, there was no denying that with no provision to ensure safety, ASHAs were vulnerable to violence and their security was a threat. This was corroborated by Junali who expressed her concern about returning home alone after completing the work at a health facility.

"You understand sister, some of our women are in XY village...some in YY [name of the villages anonymised]. The way we live in the village, we feel scared when we accompany [pregnant women] for delivery and then we have to go the [health facility] office, how will I come [home] alone."

Even as drivers and others felt that ASHAs would shield them from violence meted out by army personnel, this placed additional burdens on ASHAs and was not always the case.

\section{Community trust and acceptance}

We found that ethnic conflict in both the districts had broken the social fabric in the community, in turn affecting ASHAs and their performance. Non-acceptance of ASHAs belonging to opposing ethnic communities was an articulated concern, particularly when the population catered by ASHA comprised of 
people belonging to a different ethnic community. Even though ASHAs did not mention their fear specifically, it was evident during the discussion that there was hesitation to visit hamlets belonging to certain communities, particularly when ASHA and the villagers belonged to conflicting communities.

Sarita noted that women belonging to other communities were inhibited in reaching to her for health advice although her community was not involved in the conflict. She further mentioned that those affected - the Bengali Muslim community - believed that her community conspired with the Bodo community in burning their houses. As a result, she noted, this community stopped trusting her. It is noteworthy to mention that ASHAs were also vulnerable to the hostile attitudes of the community and faced threats when the trust was lost between communities.

"It affected me as [Bengali speaking] Muslims did not believe me. The conflict was between Bodo and Muslim communities but the Muslim thought that my community was also involved in burning their houses.

They kept to themselves and stopped coming to me for pregnancy care. The young Muslim boys were furious during the time of conflict and they tried to threaten me but I calmly explained to them. Now things have improved and Muslims in my area love me."

Notwithstanding the above, it's important to note that the inhibition and lack of trust were declining, especially in areas where there had been a long period of relative peace. This was mentioned by ASHAs and also observed during our fieldwork. We observed at the time of interview that women belonging to the Bengali speaking Muslim community visited Sarita at her home.

\section{Vulnerabilities faced by ASHAs experiencing conflict}

\section{Loss of family members}

We found that ASHAs had experienced conflict much the same way the community did. Their family members were killed, injured, tortured, or went missing, while others experienced psychosocial distress. ASHAs also suffered the effects of conflict during and after due to resource depletion and dislocation, just as other members of their communities.

One ASHA, Jennifer [name changed] lost her husband in conflict as he went missing. According to Jennifer, her husband and other men from the community were attending a peace meeting when the ethnic conflict started. She and her two daughters and sister-in-law were alone at home when they got to know about the conflict. Her youngest daughter was a week old new-born. Her daughters, sister-in-law and she ran for their lives and reached the first of many relief camps, never able to return home for fear of further violence.

While narrating her experience, Jennifer mentioned that "I took her [youngest daughter] for some time and I was unable to run properly and my elder daughter was also running. Everyone in our family ran and I was left behind. My sister-in-law helped me and took her [youngest daughter]. We stayed the night at XX [place and camp name withheld]. Her father [Jennifer's husband] didn't come and we couldn't find him. We lost all our property and land. I stayed near the camp area and never returned home." 


\section{Displacement}

We found that internal displacement - temporary or permanent- during the conflict was experienced by ASHAs. Displacement had significantly affected their living conditions, particularly among ASHAs in Kokrajhar district. As they had experienced repetitive conflict since the 1990s. Like for other members of the community, displacement due to the conflict had led to the loss of farmland, livestock, and occupation of their family members. Jennifer, for example, had suffered permanent displacement after she decided to stay back in the area where relief camp was established as she believed that the current place was more secure than her native village.

Similarly, Junali [name changed] and her family were internally displaced multiple times since 1996. Figure 2 summarizes the repeated displacement from 1996 until 2005. Junali noted that after the first conflict in 1996 her family stayed in a relief camp near block headquarters for one year before returning to the native village in 1998. After staying for a year in the village, they were again displaced for seven years. She and her family stayed in a relief camp. Out of fear of displacement, her family bought a plot in the area close by to the relief camp but returned to their native village in 2005. However, in 2012, another round of conflict occurred and they had to leave their village again. The family decided to stay back and built a house in the newly purchased plot. Junali informed that almost all natives of her village had left their village and were staying in villages close by to her current residence.

\section{Job Insecurity}

At the time of the interview, Jennifer was supporting her youngest daughter's education by working as an ASHA and operating a small shop in the village. She had also adopted an orphaned boy whom she found in one of the relief camps. Being the only earning member of the family, Jennifer was in fear of losing her job because households in her area were opting for family planning, hence there were fewer pregnant women compared to other villages. Given the thrust on institutional deliveries under a conditional cash transfer scheme known as Janani Suraksha Yojana, this incentive per pregnant woman was the main source of incentive for ASHAs. Jennifer who joined as ASHA in 2008, was afraid of losing her incentives and even worse, her job altogether:

"Now, I am working as an ASHA. What is ASHA's salary? And there are no pregnant women in my area ma'am. Income is there in an area where pregnant women are there. The Government is asking to leave but where will I find another job?"

We found that ASHAs in Kokrajhar were living in constant fear and insecurity. We observed that the health system was concerned about ASHAs performance in terms of rendering health services, meeting the planned targets, and being available whenever called for duty. We did not see, on the part of the health system, an investment in understanding or addressing the challenges and vulnerabilities faced by ASHAs as health workers and community members, even as these would directly affect their performance and the envisioned targets of the health system. 


\section{Discussion}

This paper has focused on the experiences of community health workers (CHW) working in conflict-affected parts of India and has demonstrated several challenges to the lives and livelihoods of the CHW. Notwithstanding this, all ASHAs have demonstrated resilience during the conflict and are continuing their work by overlooking the health system's inability to recognize or respond to their vulnerabilities.

The situation of the geographic region we covered is unique. The concentration of conflict in certain districts - as well as the lack of recognition of conflict by the states in the region- has meant that ASHAs' challenges and vulnerabilities in these situations and locations are yet to receive attention from state and federal policymakers. In contrast, conflict in the state of Chhattisgarh has been recognised, Left Wing Extremist (LWE) areas have been designated such that services and special schemes are being delivered in these areas through academics and partnerships with a public purpose(15). The role of civil society in areas with large tribal populations and conflicts such as Gadchiroli in Maharashtra has been significant(16). We suggest Assam, like Chhattisgarh, to first recognize challenges and vulnerabilities that ASHAs working in these areas continue to experience.

We suggest Ministry of Health to play a pivotal role in facilitating and supporting the States with conflictaffected areas to design a support mechanism for ASHAs working in fragile settings, as ASHA programme in India is sponsored scheme by the federal Ministry of Health under National Health Mission. While designing a support system for ASHAs, the health systems must be mindful that workers deserve adequate training, support, recognition, and compensation for the tasks they are carrying out in areas and situations where other cadres and workers are simply unavailable. We suggest health systems to consider incentivising the ASHAs when they provide services during conflict. We also suggest psychological support and job security for ASHAs working in fragile and conflict settings, which has already been raised as an important need in outbreak contexts (17).

This would be an important step as global literature suggests that in conflict settings, CHWs role becomes more vital as they provide key links to the community and significantly outnumber formal health workers, often acting as the only serving, resident health care worker in insecure areas(18). It is evident from the literature on human resources for health that $\mathrm{CHWs}$ are recognized as a critical cadre in the last mile or doorstep healthcare delivery in both conflict and non-conflict settings $(1,6,17,19)$. For instance, in conflictaffected countries like Afghanistan, Sierra Leone, Liberia, and the Democratic Republic of Congo, CHWs played an important role in providing a basic package of health services to the community and managing outbreaks such as Ebola $(6,18,20)$. In cases of protracted conflict, as in Palestine and Lebanon, small scale CHW programmes have shown feasibility and some results $(21,22)$, although there is a need for more research in this area, in India and globally.

Besides, considering the gap in research evidence, we suggest further in-depth study in different types of conflict, globally, for generating empirical evidences that can inform policy and decision-making. A similar knowledge gap is in understanding CHWs' challenges and vulnerabilities globally in conflict settings. The 
predominant concern of the global public health community working in fragile and conflict-affected settings is with delivering on targets - mostly related to contact coverage. This approach narrowly focuses on determinants of CHWs' performance such as training, supervision and incentives, and supplies. Only a few studies have reported physical and emotional trauma, social, gender, and cultural norms faced by $\mathrm{CHWs}$ working in fragile and conflict settings $(6,23)$. Gilmore et al have reported that $\mathrm{CHWs}$ face safety and insecurity issues, disconnect from social systems, and under-resourced working conditions during the conflict, and despite these challenges had shown resilience (5).

Our study corroborates these findings: we found ASHAs showing tremendous courage and resilience in the face of hardship to provide institutional births and basic health services. Conflict not only weakened their efforts to transport the women to a health facility for childbirth, but it also broke social relations, particularly when the conflict was based on ethnicity. This increased distrust and indifference towards ASHAs in the community. What is noteworthy to find that amidst fear and recognition of indifferent attitudes towards them, ASHAs continued to render services to the community and rebuilt the relationship with them over time. This, however, cannot be generalized as we believe there are narratives and experiences of ASHAs where they have had to bear the brunt of the breakdown of social relations and may have left the job or were reluctant to reach out to the community belonging to different ethnic communities.

Another key impact of conflict is displacement. Based on our findings and those of previous studies in fragile and conflict settings, it is evident that communities are vulnerable to displacement(24-27) and CHWs, being a part of the community, are no exception. We know that the displacement of populations is among the most severe consequences of contemporary conflicts. We have seen that ASHAs in our study settings had experienced both temporary and permanent displacement, because of the repeated conflicts. They are uprooted from their home and forced to settle in a new area. This is likely associated with psychological trauma and burnout. Gilmore et al suggest that conditions for a good CHW programme include appropriate incentives, strong work factors such as training, supervision, security, and consideration for the individual and community context(5). In the recent context of the COVID-19 pandemic as well, the safety and security of frontline health workers, as well as the stigma faced by them, have been raised as critical issues for the health system to address(17). We suggest health systems to actively engage with existing structures in the villages such as village development committee, village health, and sanitation committee or peace committees to ensure safety and security of $\mathrm{CHWs}$ as well as establishing an environment for them to perform their tasks. In addition, health system must provide pick and drop transport facility to CHWs engaged in relief camps or any health service during conflict, as a measure to ensure their safety.

A review of the ASHA programme has also raised the specific gendered challenges faced by these women workers in having to carry out unpaid labour at work and home (28). Another factor mentioned in prior work is unpaid labour or compensation for the services and expenses (such as travel) incurred by them(29). Our findings suggest that $\mathrm{CHWs}$ are no exception and that these vulnerabilities are enhanced in conflict situations. The health system must be mindful of not replicating the inequitable gender norms that may lead to the exploitation of $\mathrm{CHWs}$.

Critically, the health system's emphasis and incentivisation on maternal and child health as well as family planning - although essential - also creates perverse situations where successful family planning results in 
fewer pregnancies and thus lower compensation and job insecurity for this cadre of workers. ASHAs we spoke to have no training or system support to deal with trauma, injury, mental health challenges, which are more prevalent and affecting a broader segment of the population she serves. The need for CHWs to cover a wider range of groups - including those in conflict, to provide a continuum of care - rather than just Maternal and Child Health, and to serve and be supported as advocates for their communities is critical(30). The lack of attention to these dimensions poses a large human toll in terms of morbidity and mortality in conflict. We suggest incorporating psychological first aid in the ASHA training to equip them with basic skills related to mental health and well-being. This skill will help them in coping with their stress, and anxiety as well as the community they are serving. The psychological first aid training was found to be an important skill during the Ebola crisis in Sierra Leone and had a positive impact(31). Concurrently, we also believe that having access to psychosocial support services such as counselling during and after the conflict will help ASHAs to take responsibility for their lives and the community at large.

Globally, conflict and violence are currently on the rise: as community members themselves, the role of CHWs as the first response in emergencies is vital. This is currently evident in the COVID 19 outbreak where CHWs are the first line of defense $(17,32)$. For example, in India ASHAs are playing a pivotal role in reducing the impact of COVID 19 - they undertaking contact tracing and monitoring of home quarantined persons. The World Health Organization suggests equipping, training, and preparing CHWs to provide critical care and help to ensure equity in health at the community level. The work of CHWs will contribute to a country's effort to ensure health care for all during the crisis.

While this is important, we cannot negate the fact that it is time for the global public health community to recognize that $\mathrm{CHWs}$ are not only health workers but also as a member of the community with challenges and vulnerabilities of their own. To ensure the quality of health services in fragile and conflict settings it is important to be reflective of $\mathrm{CHWs}$ needs and design a robust support system including post-conflict recovery so that it provides a sense of security as well as reduces $\mathrm{CHWs}$ vulnerabilities.

\section{Limitations}

The number of women we were able to speak to in our field sites was limited and their situations may not be generalisable to ASHAs in other situations. Our aim, however, was to emphasise workers in these precise contexts as we feel their situation is less understood. Emphasis was instead placed on the depth and detail of interviews with these workers. What is more critically absent are the perspectives of ASHAs who may have left their work due to conflict. We were also not able to closely probe into the dynamics of ASHAs with other workers on the or at the facility and higher levels frontline (although in many cases, other workers were simply not there). Further research should also examine the roles and experiences of ASHAs in different types of conflict, ideally across Indian states with varying responses to the conflict to determine ways forward.

\section{Conclusions}

This is among the first studies in India examining the experiences of community health workers, specifically ASHAs, delivering care, and living in conflict situations. We noted the salience of simple social determinants of health, like transport, labour security, as well as the challenges of displacement and loss. The issue of trust 
- vitiated in conflict - was also noted. Conflict must be recognised as an important context within which community health workers operate, with greater policy focus and research devoted to understanding and addressing their professional and societal barriers, and greater system support to CHWs working in such conditions to enable them to perform their duty even in the face of the challenging situation.

\section{Abbreviations}

ASHA - Accredited Social Health Activist

CHW - Community Health Workers

PHC- Primary Health Center

SC- Sub Centre

\section{Declarations}

\section{Ethics approval and consent to participate}

We received ethical approval from the Ethics Review Committee ( TRC-IEC-329/17) of the Public Health Foundation of India. To preserve the anonymity of participants, all names have been changed. Written consent of participants was taken prior to the interview.

\section{Consent for publication}

Not applicable

\section{Availability of data and materials}

Not applicable

\section{Competing Interest}

None to declare

\section{Funding}

The larger study was funded by the Indian Council of Medical Research and Indian Council of Social Science Research, Government of India. Support for publishing is gratefully acknowledged from the Health Equity Action Lab (HeaL) of the George Institute for Global Health. 


\section{Author's contribution}

PR led the study design, data collection, analysis, conceptualized and drafted the manuscript. DN and AS participated in study design, data analysis, and drafting the manuscript. The views expressed herein are those of the author (s) and do not reflect the views of the World Food Programme. All authors read and approved the final manuscript.

\section{Acknowledgment}

We are grateful to the participants in this study for taking the time and sharing their experiences. The authors acknowledge the contribution of Purni Biswas, Jharna Narzary, Unish, and Jecinta for their support in data collection. We thank the Centre for North-East Studies and Policy Research, and North-East Research and Social Networking for their guidance and support during fieldwork.

\section{References}

1. Agarwal S, Curtis SL, Angeles G, Speizer IS, Singh K, Thomas JC. The impact of India's accredited social health acitivit (ASHA) program on the utilization of maternity services: a nationally representative longitudinal modelling study. Hum Resour Health. 2019 Aug 19;17(68).

2. Marwa AA, Thrift AG, Riddel M, Kavumpurathu RTT, Gomathyamma KM, Clara KC, et al. Evaluation of a training program of hypertension for accredited social health activists (ASHA) in rural India. BMC Health Serv Res. 2018 Feb 5;18(1):320.

3. Saprii L, Richard E, Kokho P, Theobald S. Community health workers in rural India: analysing the opportunities and challenges Accredited Social Health Activists (ASHAs) face in realising their multiple roles. Hum Resour Health. 2015 Sep 12;13(95).

4. Scott K, George AS, Ved RR. Taking stock of 10 years of published research on the ASHA programme: examining India's national community health worker programme from a health systems perspective. 2019 Mar 25;17(29).

5. Gilmore B, Adams BJ, Bartoloni A, Alhaydar B, McAuliffe E, Raven J, et al. Improving the performance of community health workers in humanitarian emergencies: a realist evaluation protocol for PIECES programme. BMJ Open. 2016;6(e011753).

6. Najafizada SAM, Labonté R, Bourgeault IL. Community health workers of Afghanistan: a qualitative study of a national program. Confl Health. 2014 Jan 12;8(26).

7. Registrar General of India. Assam Profile [Internet]. 2011 [cited 2020 Dec 5]. Available from: https://censusindia.gov.in/2011 census/censusinfodashboard/stock/profiles/en/IND018_Assam.pdf

8. Second Administrative Reforms Commission. Capacity building for conflict resolution [Internet]. New Delhi: Second Administrative Reforms Commission, Government of India; 2008 Feb p. 143. Available from: https://darpg.gov.in/sites/default/files/capacity_building7.pdf

9. The Ant. Health inequities in a conflict area- An in-depth qualitative study in Assam. Assam: The Action Northeast Trust; 2017 p. 160. 
10. Singh A. Conflicts in Assam. Bangalore: National Institute of Advanced Studies; 2010.

11. Narzary RK. Impact of conflict on children in Assam and Manipur states in India. Assam: The Northeast Research and Social Work Networking; 2014 p. 40.

12. The Economic Times. A distraut tribal: The genesis of Assam ethnic violence. The Economic Times: Politics and Nation [Internet]. 2012 Aug 12 [cited 2018 Dec 12]; Available from: https://economictimes.indiatimes.com/news/politics-and-nation/a-distraught-tribal-the-genesis-ofassam-ethnic-violence/articleshow/15458830.cms?from=mdr

13. MoHFW. National Rural Health Mission: Meeting people's health needs in rural areas, framework for implementation (2005-2012) [Internet]. Ministry of Health and Family Welfare; [cited 2020 Jan 4]. Available from: https://nhm.gov.in/WriteReadData/l892s/nrhm-framework-latest.pdf

14. Charmaz K. Constructing Grounded Theory: A practical guide through qualitative analysis. In London: Sage Publication Inc; 2006.

15. Sharma S. In Chhattisgarh's red corridor,mobile clinics go where no doctors have been. Hindustan Times [Internet]. 2016 Oct 25 [cited 2020 May 31]; Available from: https://www.hindustantimes.com/indianews/in-chhattisgarh-s-red-corridor-mobile-clinics-go-where-no-doctors-have-been/storyDsf4k6f3hlsfw2U0QrFKGL.html

16. Sharma G. Health care through community participation: a policy initiative in reference to tribal areas in India [Internet]. Bangalore: Indian Institute of Management; 2016 [cited 2020 Jan 6]. Available from: https://repository.iimb.ac.in/handle/123456789/8124

17. Bhaumik S, Moola S, Tyagi J, Nambiar D, Kakoti M. Community health workers for pandemic response:a rapid evidence synthesis [Internet]. MedRxiv - The preprint server for health services; 2020 [cited 2020 May 28]. Available from: https://www.medrxiv.org/content/10.1101/2020.04.28.20082586v1

18. Martineau T, McPake B, Theobald S, Raven J, Ensor T, Fustukian S, et al. Leaving no one behind: Lessons on rebuilding health systems in conflict- and crisis-affected states. BMJ Glob Health. 2017 May 26;

19. Lehmann U, Sanders D. Community health workers: What do we know about them? The state of the evidence on programmes,activities,costs and impact on health outcomes of using community health workers [Internet]. Geneva: World Health Organization; 2007. Available from:

https://www.who.int/hrh/documents/community_health_workers.pdf

20. Miller NP, Milsom P, Johnson G, Bedford J, Kapeu AS, Diallo AO, et al. Community health workers during the Ebola outbreak in Guinea,Liberia, and Sierra Leone. J Glob Health. 2018;8(2):020601.

21. Atallah D, Kramer S, Bast LA, Stanley B, Scales D, Jawabreh N, et al. Community health worker under occupation:Towards the development of a new model to address social and political determinants of health in Palestinian refugee camps [Internet]. [cited 2020 Jun 20]. Available from:

https://chwcentral.org/community-health-work-under-occupation-towards-the-development-of-a-newmodel-to-address-social-and-political-determinants-of-health-in-palestinian-refugee-camps/

22. Filling that gap. Fill that gap supports community health workers in Lebanon [Internet]. Health Europa. 2019 [cited 2020 Jun 20]. Available from: https://www.healtheuropa.eu/fill-that-gap-supportscommunity-health-workers-in-lebanon/95117/ 
23. Percival V, Richards ED, Wurie H, Namakula J, Ssali S, Theobald S. Are health systems interventions gender blind? examining health system reconstruction in condlict affected states. Glob Health. 2018;14(90).

24. Medecins Sans Frontieres. Forced to flee-Women's health and displacement [Internet]. Medecins Sans Frontieres; [cited 2018 Dec 4]. Available from: https://www.msf.org/forced-flee-womens-health-anddisplacement

25. Bradley M. The impact of armed conflict on displacement [Internet]. Institut Barcelona d'Estudis Internacionals; 2017 [cited 2020 Jul 16]. Available from: https://www.researchgate.net/publication/327976746_The_Impact_of_Armed_Conflict_on_Displacement

26. Burns R, Wickramage K, Musah A, Siriwardhana C, Checchi F. Health status of returning refugees, internally displaced persons, and the host community in a post-conflict district in northern Sri Lanka: a cross-sectional survey. Confl Health. 2018;12(41).

27. IDMC. Global report on internal displacement [Internet]. Geneva: Internal Displacement Monitoring Centre; 2019 [cited 2020 Dec 5] p. 159. Available from: https://www.internaldisplacement.org/sites/default/files/publications/documents/2019-IDMC-GRID.pdf

28. Ved R, Gupta G, Ummer O, Srivastava A, George AS. How are gender inequalities facing India's one million ASHAs being addressed? Policy origins and adaptations for the world's largest all-female community health worker programme. Hum Resour Health. 2019;17(3).

29. George A. Nurses, community health workers, and home carers: gendered human resources compensating for skewed health systems. Glob Public Health. 2008;3 suppl 1:75-89.

30. Ved R. Paradigm shifts in community health workers role to address non-communicable diseases [Internet]. [cited 2020 Jun 20]. Available from: https://www.georgeinstitute.org/profiles/paradigm-shiftsin-community-health-worker-roles-to-address-non-communicable-diseases

31. Walker P, McGrath M, Schafer A. CHWs and mental health: Equipping community health workers with essential skills for addressing mental health and violence in the home [Internet]. CHW Central: A global resource for and about Community Health Workers. [cited 2020 Jun 20]. Available from: https://chwcentral.org/chws-and-mental-health-equipping-community-health-workers-with-essentialskills-for-addressing-mental-health-and-violence-in-the-home/

32. Endeva. COVID 19: a key role for community health workers [Internet]. 2020 [cited 2020 Jul 16]. Available from: https://endeva.org/blog/covid-19-a-key-role-for-community-health-workers

\section{Figures}




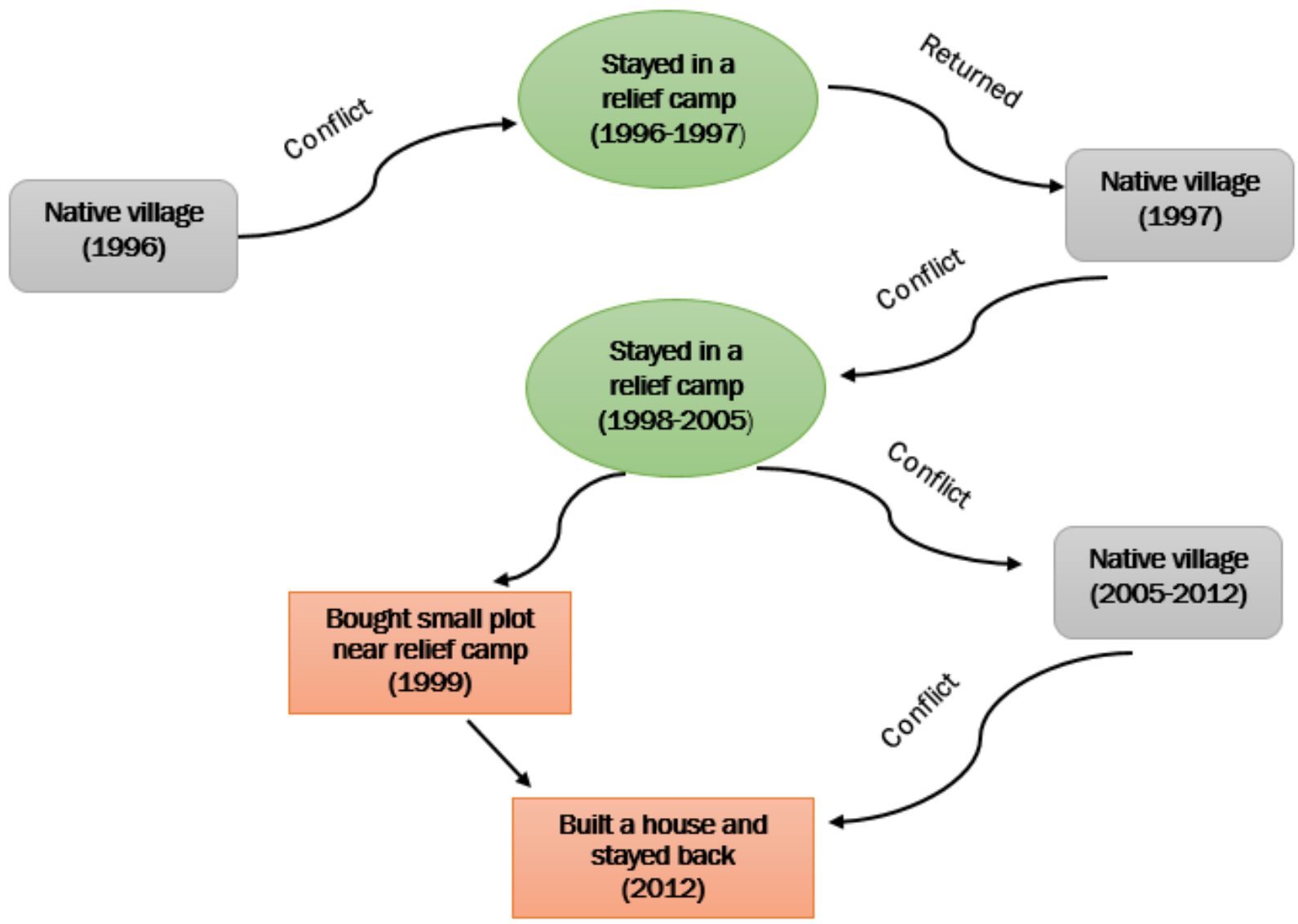

Figure 1

ASHA as a member of the community is susceptible to displacement Source: Authors, based on Junali's interview 


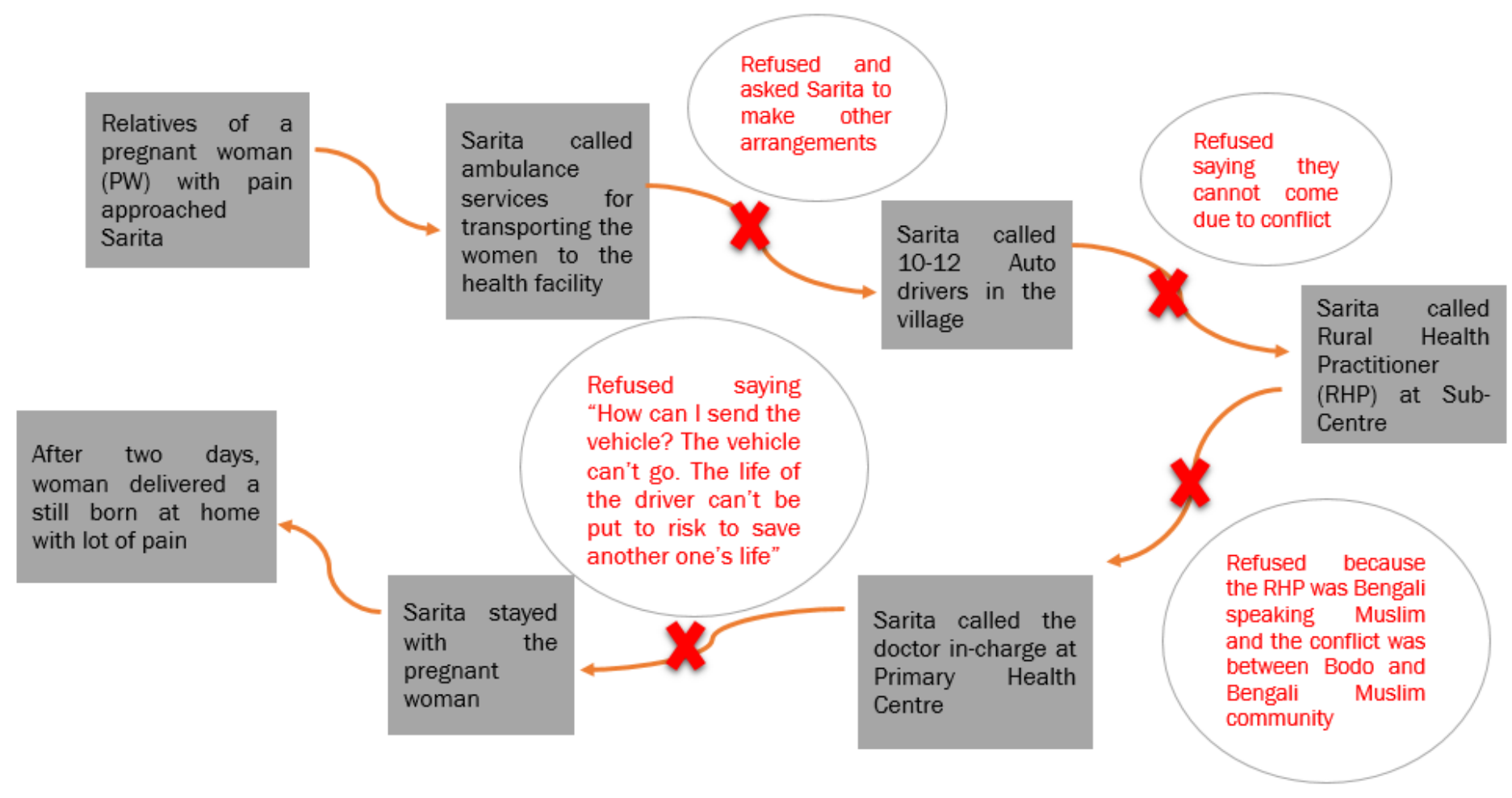

Figure 1

ASHA's narrative regarding delivery services during the conflict Source: Authors, based on Sarita's interview 